\title{
Article \\ Circulating miRNAs Act as Diagnostic Biomarkers for Bladder Cancer in Urine
}

\author{
Jen-Tai Lin ${ }^{1}$ (D) and Kuo-Wang Tsai ${ }^{2, * \mathbb{D}}$ \\ 1 Division of Urology, Department of Surgery, Kaohsiung Veterans General Hospital, \\ Kaohsiung 813414, Taiwan; jtlin@vghks.gov.tw \\ 2 Department of Research, Taipei Tzu Chi Hospital, Buddhist Tzu Chi Medical Foundation, \\ New Taipei 23142, Taiwan \\ * Correspondence: kwtsai6733@gmail.com
}

Citation: Lin, J.-T.; Tsai, K.-W.

Circulating miRNAs Act as

Diagnostic Biomarkers for Bladder Cancer in Urine. Int. J. Mol. Sci. 2021 22, 4278. https://doi.org/10.3390/ ijms22084278

Academic Editor:

Juan Gilabert-Estellés

Received: 31 March 2021

Accepted: 19 April 2021

Published: 20 April 2021

Publisher's Note: MDPI stays neutral with regard to jurisdictional claims in published maps and institutional affiliations.

Copyright: (c) 2021 by the authors. Licensee MDPI, Basel, Switzerland. This article is an open access article distributed under the terms and conditions of the Creative Commons Attribution (CC BY) license (https:// creativecommons.org/licenses/by/ $4.0 /)$.

\begin{abstract}
MicroRNAs (miRNAs) can be secreted into body fluids and have thus been reported as a new type of cancer biomarker. This study aimed to determine whether urinary miRNAs act as noninvasive biomarkers for diagnosing bladder cancer. Small RNA profiles from urine were generated for 10 patients with bladder cancer and 10 healthy controls by using next-generation sequencing. We identified 50 urinary miRNAs that were differentially expressed in bladder cancer compared with controls, comprising 44 upregulated and six downregulated miRNAs. Pathway enrichment analysis revealed that the biological role of these differentially expressed miRNAs might be involved in cancer-associated signaling pathways. Further analysis of the public database revealed that let-7b-5p, miR-149-5p, miR-146a-5p, miR-193a-5p, and miR-423-5p were significantly increased in bladder cancer compared with corresponding adjacent normal tissues. Furthermore, high miR-149-5p and $m i R-193 a-5 p$ expression was significantly correlated with poor overall survival in patients with bladder cancer. The qRT-PCR approach revealed that the expression levels of let-7b-5p, miR-149-5p, $m i R-146 a-5 p$ and $m i R-423-5 p$ were significantly increased in the urine of patients with bladder cancer compared with those of controls. Although our results indicated that urinary miRNAs are promising biomarkers for diagnosing bladder cancer, this must be validated in larger cohorts in the future.
\end{abstract}

Keywords: bladder cancer; microRNA; circulating miRNA; biomarker

\section{Introduction}

Among men worldwide, bladder cancer ranks as the ninth most common cancer and 11th in terms of mortality [1]. The male-to-female bladder cancer incidence ratio is approximately 5:2, with smoking considered the reason for male predominance [2]. Most patients with advanced bladder cancer present with painless gross hematuria sometimes accompanied by the sensation of urgently needing to urinate, and even urge incontinence. In terms of survival outcomes, the five-year relative survival rates of advanced bladder cancer have seen little improvement. When a patient is suspected of having bladder cancer, the initial assessment involves cystoscopy and imaging of the urinary tract through techniques such as sonography and computed tomography urography. However, tiny papillary tumors and carcinoma in situ are difficult to detect using standard white-light cystoscopy or urinary tract imaging, which may account for the misdiagnosis or early recurrence of bladder cancer. This difficulty has led scientists to develop new cystoscopic techniques, such as narrow-band imaging cystoscopy and photodynamic diagnosis. Previous studies have identified numerous noninvasive biomarkers in urine that can serve as diagnostic indicators of bladder cancer [3]. Comprehensive screening approaches have been applied to urine samples to identify cell-free DNA, cell-free RNA, small RNA, or DNA methylation in cells, including DNA methylation of PCDH17 and POU4F2 [4], as well as determine circulating mRNA levels of IGFBP5, HOXA13, MDK, CDK1, and CXCR2 [5] and the mutation status of FGFR3 and TERT promoters [6]. Some urine-related biomarkers have been approved for 
clinical use by the United States Food and Drug Administration (FDA), such as nuclear matrix protein 22 [7], human complement factor H-related protein [8], carcinoembryonic antigen [9], and sulfated mucin glycoprotein [10]. These biomarkers are typically used in conjunction with cystoscopy to increase the diagnostic sensitivity and specificity for bladder cancer. However, these FDA-approved biomarkers have the shortcoming of a high false-positive rate in patients with inflammatory conditions. To date, the diagnosis of early bladder cancer remains difficult; therefore, the development of noninvasive biomarkers for early diagnosis will be highly beneficial for patients with bladder cancer.

Numerous noncoding RNAs have been constitutively transcribed from human genomic DNA. Among them, small RNAs (approximately 21 to 23 nucleotides long) are microRNAs (miRNAs), which play critical roles in human disease processes [11]. In general, miRNAs exert their biological functions through binding the $3^{\prime}$-untranslated region of protein-coding genes, resulting in the degradation of messenger RNAs or destruction of the protein translation process. Therefore, miRNAs might play distinct roles depending on their targeting genes during cancer progression [12-20]. Recently, numerous studies have reported that miRNAs can be secreted from cells through exosome particles into body fluids, including blood, urine, tears, and gastric juice [21-23]. As circulating miRNAs are packaged in exosome particles, they are protected from RNase degradation. These stable circulating miRNAs could act as noninvasive biomarkers reflecting certain physiological statuses, including cancer [22,24]. To date, numerous circulating miRNAs have been detected in urine, and they have potential as noninvasive diagnosis biomarkers for bladder cancer $[25,26]$. Various miRNAs have been detected in the urine of patients with bladder cancer. Pardini et al. reported that three circulating miRNAs (let-7c-5p, miR-30a-5p, and $m i R-486-5 p$ ) were differentially expressed in all bladder cancer subtypes and were accurate biomarkers for discriminating cases and controls [25]. They concluded that these circulating urinary miRNAs could act as accurate noninvasive biomarkers for the early diagnosis of bladder cancer. Another study established diagnostic panels ( $m i R-31-5 p$ and miR-93-5p) that enabled the sensitive detection of bladder cancer with areas under the receiver operating characteristic curve (AUCs) of 0.84 and 0.81 in the training and validation cohorts, respectively [27]. In addition, Du et al. analyzed small RNA profiles of urine from patients with bladder cancer and identified a group of miRNAs that were differentially expressed, which included miR-7-5p, miR-22-3p, miR-29a-3p, miR-126-5p, miR-200a-3p, miR-375, and $m i R-423-5 p$. An examination of the expression levels of these miRNAs in urine enabled accurate diagnosis of bladder cancer with AUC values of 0.923 and 0.916 in training and validation sets, respectively [28]. According to the aforementioned results, the distribution of urinary miRNAs might differ in bladder cancer in people of different ethnicities. In this study, we sought to determine whether urinary miRNAs can act as noninvasive biomarkers for diagnosing bladder cancer in Taiwanese patients.

\section{Results}

\subsection{MicroRNA Profiles Were Generated by Next-Generation Sequencing}

We collected 180 urine samples, including samples from 100 healthy volunteer controls and 80 patients with bladder cancer. Furthermore, to identify whether circulating miRNAs act as diagnostic biomarkers for bladder cancer, we analyzed small RNA profiles of urine from 10 healthy controls and 10 patients with bladder cancer through next-generation sequencing. A total of 50 circulating urinary miRNAs with differential expression were present in the bladder cancer group compared with the healthy control group (Figure 1A,B). We further identified the putative targets of these differentially expressed miRNAs and subjected them to pathway enrichment analysis. As illustrated in Figure 1C, the biological functions of these miRNA candidates were significantly involved in cancer-related signaling pathways, including those of proteoglycans in cancer, MAPK, TGF-beta, FoxO, colorectal cancer, cellular senescence, the adherens junction, PI3K-Akt, Hippo, autophagy, focal adhesion, and ErbB. Some of these signaling pathways have been reported to have a biological function in bladder cancer progression $[29,30]$. 
(A)

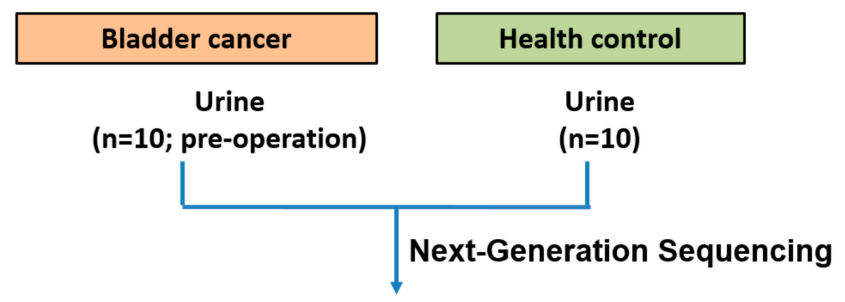

Filter: Differential expression miRNAs

Fold change $>2$

Upregulation: 44 circulating miRNAs

Downregulation: 6 circulating miRNAs

$\downarrow$
Detect five miRNA expression in
validation cohort
(Let-7b-5p, miR-146a-5p, miR-149-5p,
miR-193-5p and miR-423-5p)

(B)

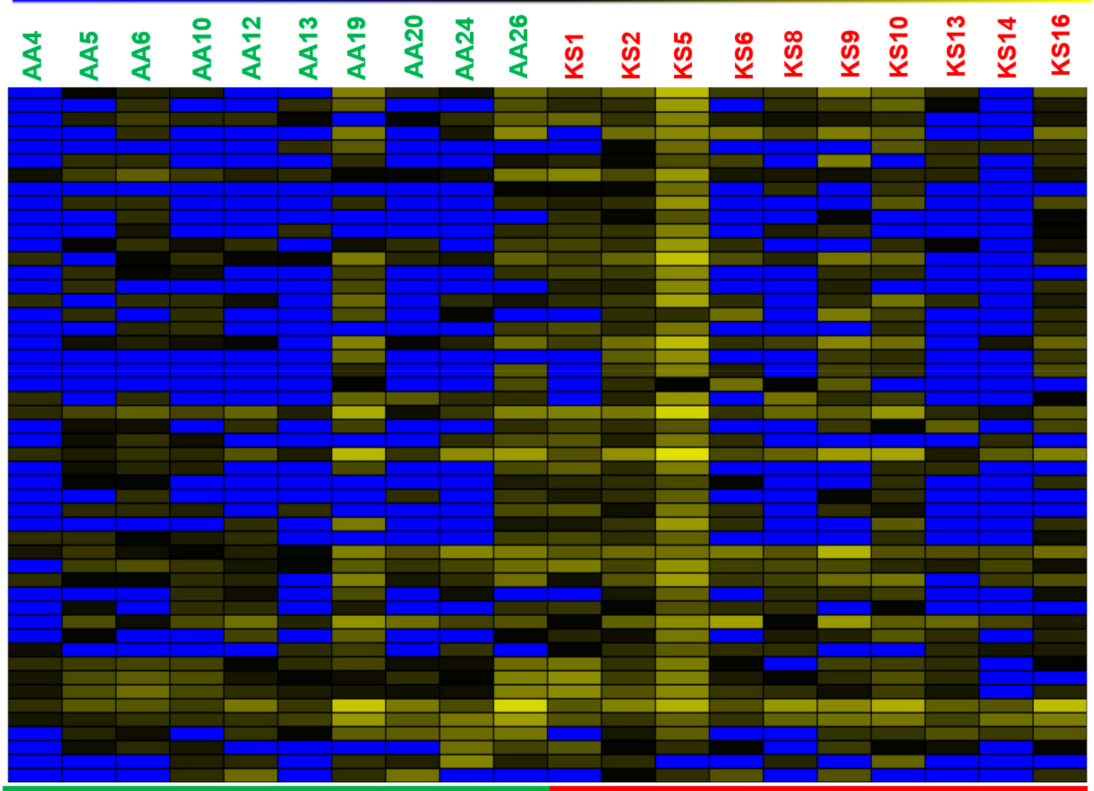

Healthy Control

Bladder Cancer

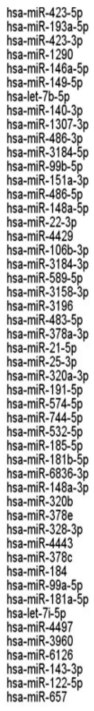

Figure 1. Cont 
(C)

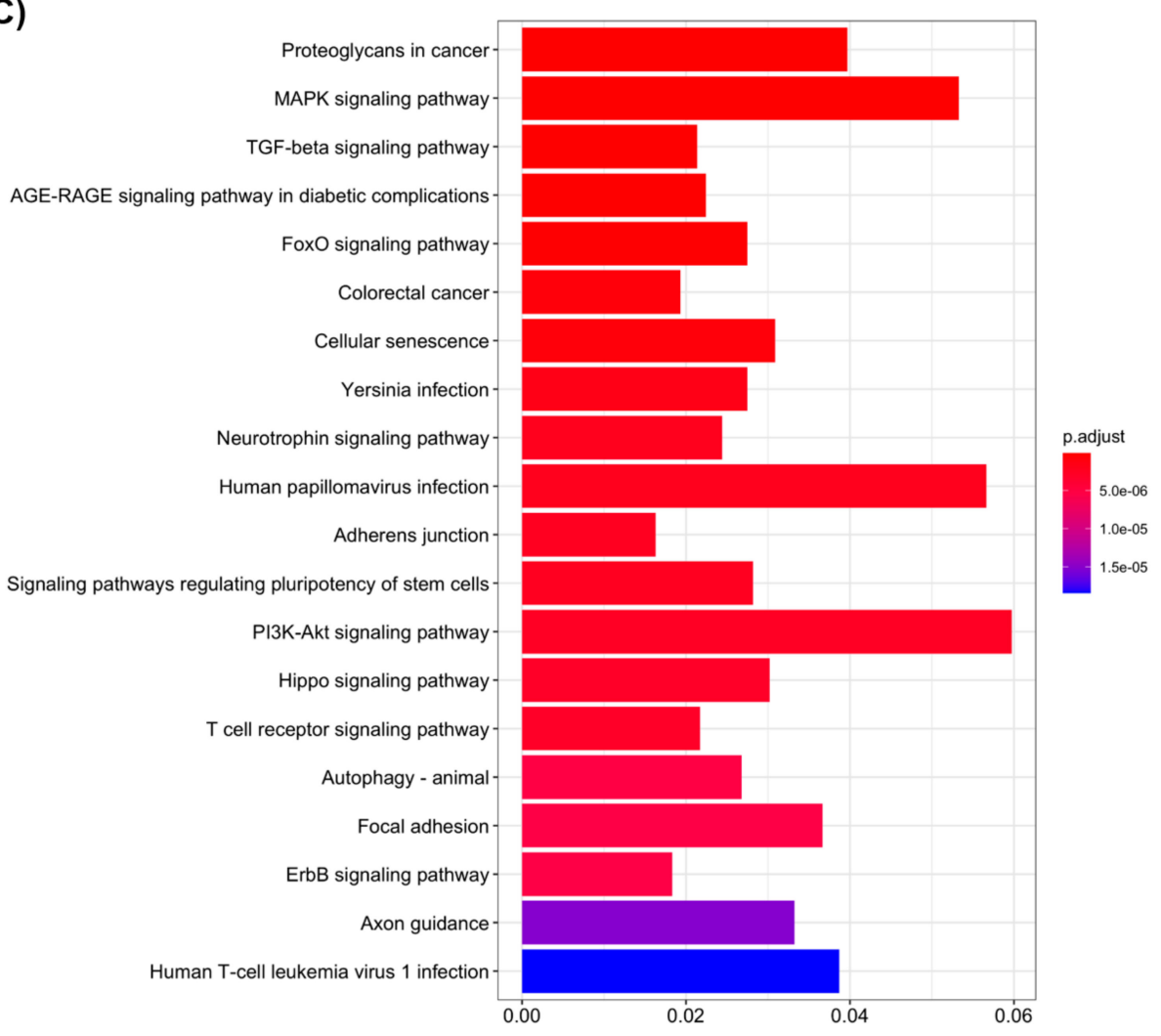

Figure 1. Differentially expressed circulating miRNAs were identified in urine from healthy volunteers and patients with bladder cancer using next-generation sequencing. (A) Flowchart of 10 NGS profiles. Circulating miRNAs with differential expression were filtered with a fold change of $\geq 2$ or $<0.25$. (B) Heatmap presenting the upregulation or downregulation of circulating miRNAs in patients with bladder cancer. (C) Targets of differentially expressed miRNA candidates were identified using a target prediction tool and pathway enrichment analysis.

\section{2. miRNAs Were Upregulated in Bladder Cancer}

Studies have revealed that cancer-associated circulating microRNAs in serum or urine are released through exosomes, which are produced by normal cells and cancerous lesions $[11,31]$. Therefore, we selected five upregulated circulating miRNAs, namely let-7b-5p, miR-146-5p, miR-149-5p, miR-423-5p and miR-193a-5p, for further examination in bladder cancer. As depicted in Figure 2, the expression levels of let-7b-5p ( $p$ value $=0.001)$, miR$146 a-5 p(p$ value $=0.001)$, miR-149-5p $(p$ value $<0.001)$, miR-193a-5 $p(p$ value $=0.02)$, and miR-423-5p ( $p$ value $<0.001$ ) were significantly increased in bladder cancer compared with corresponding adjacent normal tissues. Analysis of The Cancer Genomics Atlas (TCGA) database revealed that high miR-149-5p (crude hazard ratio [CHR], 1.52; 95\% confidence interval [CI] 1.00-2.33; $p=0.05$ ) and $m i R-193 a-5 p$ expression levels are significantly associated with a poor overall survival of patients with bladder cancer (CHR, 1.90; 95\% CI 1.29-2.78; $p=0.001$; Table 1 and Figure 3). Multivariate logistic analysis revealed that high miR-149-5p (adjusted HR [AHR], 1.70; 95\% CI, 1.11-2.61; $p=0.015$ ) and miR-193a-5p (AHR, 1.86 ; $95 \% \mathrm{CI}, 1.26-2.74 ; p=0.002$ ) expression levels were significantly associated with a poor survival curve in overall survival (Table 1). Together, miR-149-5p and miR-193a-5p could act as prognostic biomarkers for bladder cancer.

\subsection{Four Circulating miRNAs Were Highly Expressed in the Urine of Patients with Bladder Cancer}

We further examined whether let-7b-5p, miR-146a-5p, miR-149-5p, miR-423-5p, and miR-193a-5p could be expressed from bladder cancer cells at excessive levels and detected in urine to investigate whether they could be biomarkers for detecting bladder cancer. 
We analyzed the concentrations of the five miRNA candidates in 90 healthy controls and 70 patients with bladder cancer. The expression levels were assessed using TaqMan real-time PCR assays. As illustrated in Figure 4, let-7b-5p ( $p$ value $=0.0002), m i R-146 a-5 p$ $(p$ value $=0.002), m i R-149-5 p(p$ value $=0.002)$, and $m i R-423-5 p(p$ value $=0.001)$ were significantly increased in the urine of patients with bladder cancer compared with those of healthy controls. These findings indicate the aberrant expression of let-7b-5p, miR-146a-5p, $m i R-149-5 p$, and $m i R-423-5 p$ in bladder cancer, and their circulating abundance indicates that they are potential noninvasive biomarkers for detecting bladder cancer.

(A)

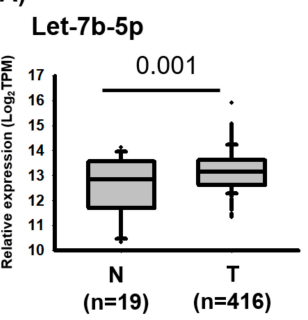

(D)

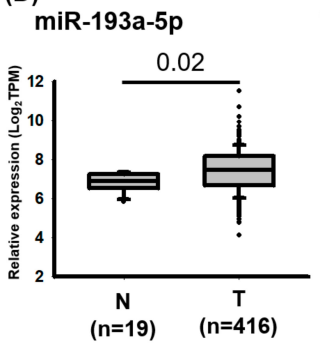

(B)

$$
\text { miR-146a-5p }
$$

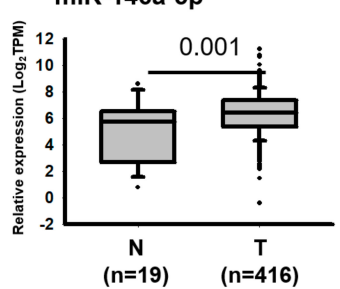

miR-149-5p

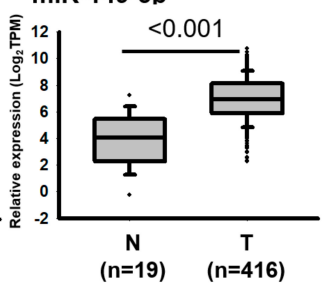

(E) $\operatorname{miR}-423-5 p$

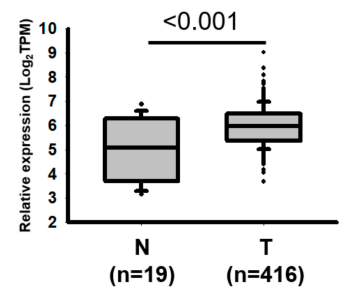

Figure 2. Expression levels of miRNA candidates in bladder cancer were revealed through an analysis of the TCGA database. Expression levels of (A) let-7b-5p, (B) miR-146-5p, (C) miR-149-5p, (D) $m i R-193 a-5 p$ and (E) $m i R-423-5 p$ were examined by analyzing The Cancer Genome Atlas database. The transcriptome profiles of 435 patients with bladder cancer were downloaded from said database, including 19 adjacent normal tissues and 416 bladder cancer tissues. The expression levels of miRNAs are presented in transcripts per million (TPM). Those of individual miRNAs were analyzed using Student's $t$ tests.

Table 1. Univariate and multivariate Cox's regression analysis of gene expression for overall survival of 405 patients with bladder cancer.

\begin{tabular}{|c|c|c|c|c|c|}
\hline \multirow{2}{*}{ Characteristic } & \multirow{2}{*}{ No. (\%) } & \multicolumn{4}{|c|}{ OS } \\
\hline & & CHR (95\% CI) & $p$-Value & AHR (95\% CI) & $p$-Value \\
\hline \multicolumn{6}{|l|}{ Let-7b-5p } \\
\hline Low & $151(37.3)$ & 1.00 & & 1.00 & \\
\hline High & $254(62.7)$ & $1.39(0.92-2.10)$ & 0.120 & $1.34(0.89-2.03)$ & 0.167 \\
\hline \multicolumn{6}{|l|}{$m i R-149-5 p$} \\
\hline Low & $122(30.1)$ & 1.00 & & 1.00 & \\
\hline High & $283(69.9)$ & $1.52(1.00-2.33)$ & 0.050 & $1.70(1.11-2.61)$ & 0.015 \\
\hline \multicolumn{6}{|l|}{$m i R-146 a-5 p$} \\
\hline Low & $68(16.8)$ & 1.00 & & 1.00 & \\
\hline High & 337 (83.2) & $1.12(0.64-1.97)$ & 0.688 & $0.94(0.53-1.66)$ & 0.832 \\
\hline \multicolumn{6}{|l|}{$m i R-193 a-5 p$} \\
\hline Low & 237 (58.5) & 1.00 & & 1.00 & \\
\hline High & $168(41.5)$ & $1.90(1.29-2.78)$ & 0.001 & $1.86(1.26-2.74)$ & 0.002 \\
\hline \multicolumn{6}{|l|}{$m i R-423-5 p$} \\
\hline Low & $30(7.4)$ & 1.00 & & 1.00 & \\
\hline High & 375 (92.6) & $1.84(0.68-4.99)$ & 0.233 & $2.09(0.77-5.70)$ & 0.148 \\
\hline
\end{tabular}

Abbreviation: OS, overall survival; $\mathrm{CHR}$, crude hazard ratio; AHR, adjusted hazard ratio. AHR were adjusted for AJCC pathological stage (II, III and IV VS. I). 
(A)

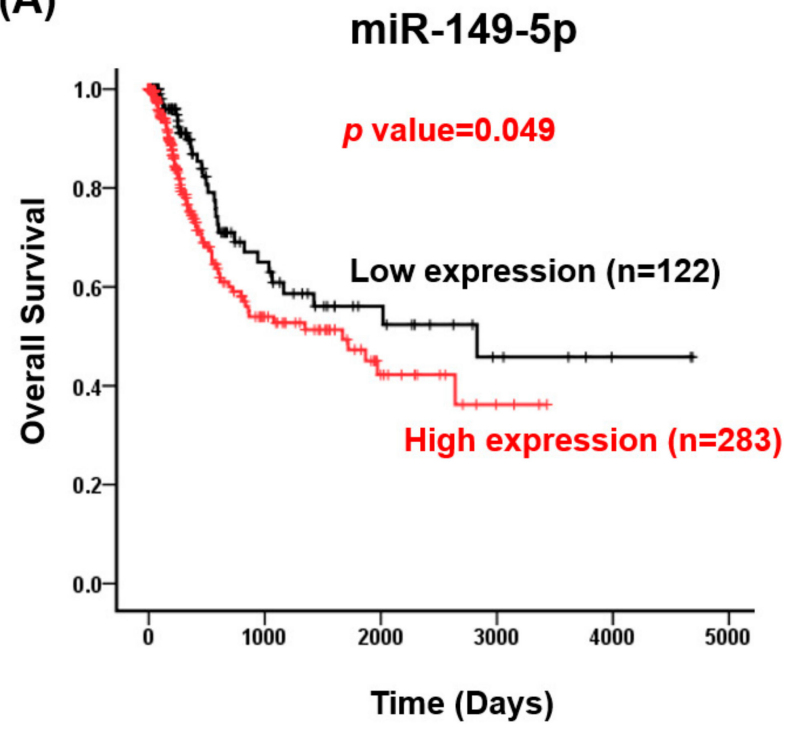

(B)

miR-193a-5p

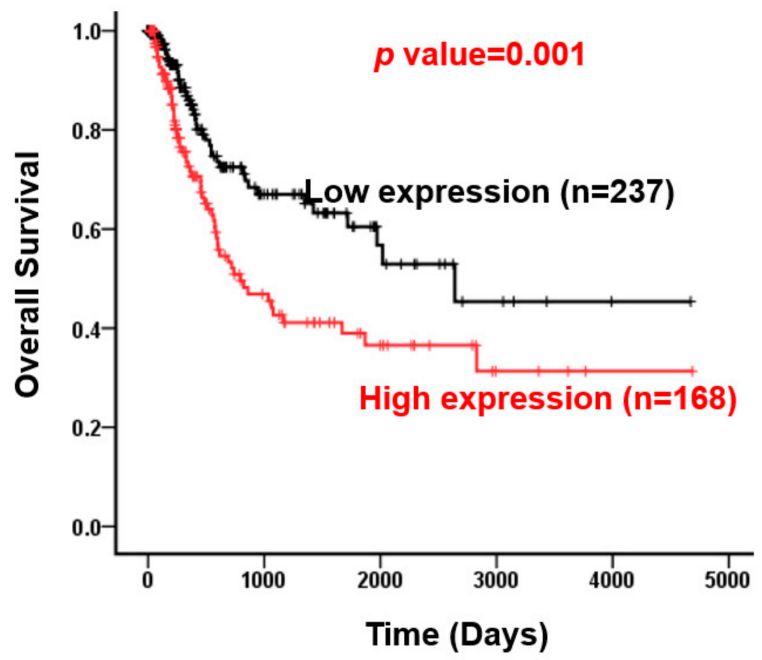

Figure 3. Expression levels of $m i R-149-5 p$ and $m i R-193 a-5 p$ were highly associated with the survival curve of patients with bladder cancer. The receiver operating characteristic curve was used to define cutoff values for miR-149-5p and $m i R-193-5 p$ expression levels. According to the defined cutoff values (69 for miR-149-5p and 199 for $m i R-193-5 p$ ), the patients were divided into groups according to whether they had high or low expression levels of miR-149-5p or miR-193-5p. The correlation between $m i R-149-5 p$ expression (A) and miR-193a-5p expression (B) was analyzed according to the overall survival curve.

(A)

\section{Let-7b-5p}

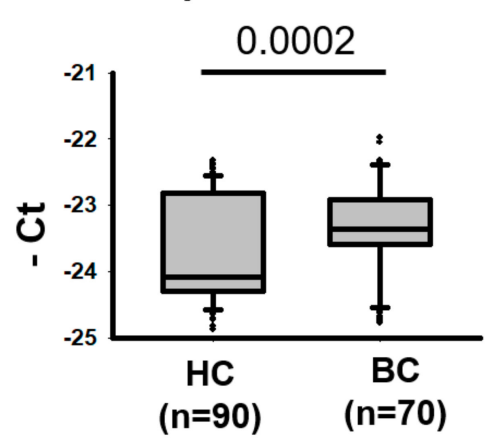

(D)

miR-193a-5p

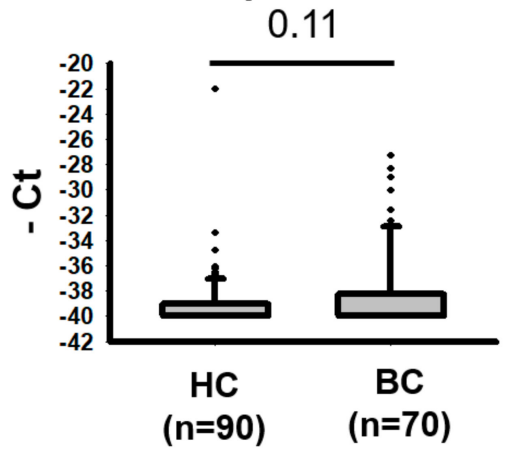

(B)

$\operatorname{miR}-146-5 p$

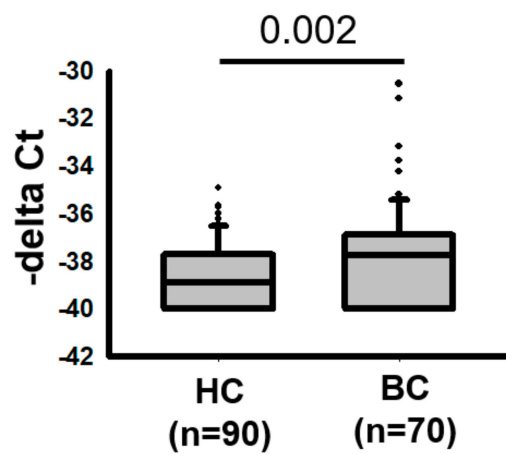

(E) miR-423-5p

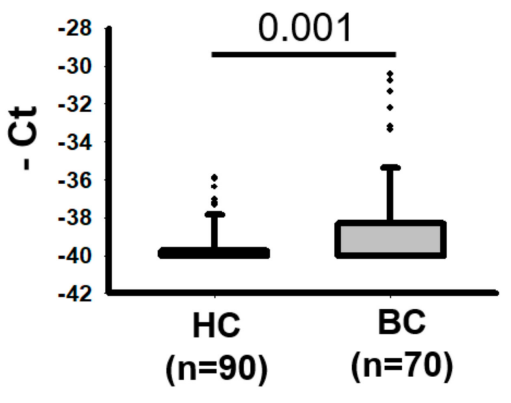

Figure 4. Expression levels of let-7b-5p, miR-146a-5p, miR-149-5p, miR-193a-5p, and miR-423-5p in urine from healthy controls and patients with bladder cancer. Relative levels of (A) let-7b-5p, (B) miR-146a-5p, (C) miR-149-5p, (D) miR-193-5p, and (E) miR-423-5p were examined in urine from 90 healthy controls and 70 patients with bladder cancer using TaqMan real-time PCR Assays. 


\section{Discussion}

Studies have revealed that different expression patterns of circulating miRNAs in body fluids might originate from different cell types under certain physiological statuses [22,24]. Therefore, miRNAs might be useful noninvasive biomarkers for diagnosing human cancers and detecting their recurrence. Our previous studies have reported that circulating miRNAs in serum could act as diagnostic biomarkers for human diseases, including gastric cancer recurrence, bipolar II disorder, and Kawasaki disease [32,33]. Other studies have revealed that several circulating miRNAs could be released into urine and thus could potentially be used as biomarkers for diagnosing human cancers, especially those of the urinary tract $[34,35]$. Moreover, one study used real-time PCR to measure the levels of miR-145 and miR-200a in the urine of patients with bladder cancer and healthy controls; the authors revealed that these miRNAs exhibited promise as noninvasive biomarkers for the diagnosis of bladder cancer and detection of its recurrence [36]. By using TaqMan Human MicroRNA Arrays, Mengual et al. were the first to globally profile urinary miRNA expression, and they identified a list of dysregulated miRNA candidates for noninvasive diagnostics biomarkers of bladder cancer, including miR-25, miR-18a*, miR-187, miR-204, miR142-3p, and miR-140$5 p$ [37]. Ghorbanmehr et al. identified three urinary microRNAs, namely miR-21-5p, miR141-3p, and miR-205-5p, as potentially strong choices for noninvasive diagnostic biomarkers for bladder and prostate cancer diagnosis [38]. According to the aforementioned findings, different research groups have identified miRNA candidates in urine that are not identical, which may be caused by different ethnicities of participants.

In another study, high levels of miRNAs expressed from tumor lesions were reported to be released into body fluid through extracellular vesicles [39]. Based on this, examining the expression levels of miRNA candidates in bladder cancer tissues and urine samples in the same cohort would have been of great interest. In the present study, we collected only urine samples from patients with bladder cancer; therefore, we did not have data on miRNA expression from bladder cancer tissue from the same patients. Furthermore, we examined the expression levels and clinical impacts of miRNA candidates in bladder cancer by analyzing the TCGA database. Due to this limitation, we were unable to conclude whether the high expression of circulating miRNAs in urine was from bladder cancer lesions.

In the present study, we compared the abundance of miRNAs in urine between healthy controls and patients with bladder cancer, revealing 50 circulating urinary miRNAs with differential expression in patients with bladder cancer. Pathway enrichment analysis indicated that these differentially expressed miRNA candidates were involved in cancer-associated signaling pathways, including the MAPK, PI3K-Akt, focal adhesion, and ErbB signaling pathways. The importance of MAPK, PI3K-Akt, and ErbB signaling in bladder cancer development was previously demonstrated in clinical, mouse, and in vitro cell models [40]. Furthermore, we examined the expression levels of let-7b-5p, miR-149-5p, $m i R-146 a-5 p, m i R-193 a-5 p$, and $m i R-423-5 p$ and found that they were significantly increased in bladder cancer compared with adjacent normal tissues. Studies have reported that circulating let-7b-5p expression exists in human plasma or serum, and thus, let- $7 b-5 p$ is a promising biomarker for detecting cancers, including breast cancer and nasopharyngeal carcinoma [41-44]. In addition, both circulating let-7b-5p and $m i R-423-5 p$ expression in plasma were significantly altered in young women who participated in long-term exercise [45]. Furthermore, recent studies have indicated that $m i R-149-5 p$ has a tumor-suppressive role in the regulation of cancer cell growth in human cancer through modulating GIT1, circNRIP1, and HNF1A-AS [46-48].

The present study is the first to report that miR-149-5p is significantly increased in bladder cancer and that high miR-149-5p expression is strongly associated with poor survival in bladder cancer. Furthermore, we provided novel results that demonstrate miR-149-5p in urine as a potential noninvasive biomarker for bladder cancer detection; miRNA-423-5p might play an opposite role in various human cancers; and $m i R-423-5 p$ expression could promote gastric cancer cell growth and invasion ability by silencing TFF1 expression [41]. $\mathrm{Li}$ et al. reported that $m i R-423-5 p$ was significantly overexpressed and that miR-423-5p 
expression accelerated glioma cell growth, angiogenesis, and invasion by activating AKT and ERK1/2 signaling [49]. By contrast, $m i R-423-5 p$ had significantly low expression in osteosarcoma tissues, and miR-423-5p expression could suppress osteosarcoma cell proliferation, colony formation, and invasion ability by targeting STMN1 expression [50]. Tang et al. indicated that expression levels of $m i R-423-5 p$ were significantly decreased in ovarian cancer and the plasma of patients with ovarian cancer compared with those in healthy individuals. Therefore, $m i R-423-5 p$ expression could act as a diagnostic biomarker and have a biological function as a tumor suppressor, inhibiting ovarian cancer cell growth and invasion [51]. To date, the biological function of miR-423-5p remains unclear in bladder cancer. In the present study, after analyzing the TCGA database, we reported that miR423-5p expression was significantly increased in bladder cancer tissues. Furthermore, the expression levels of $m i R-423-5 p$ were significantly increased in urine from patients with bladder cancer compared with healthy controls. Our data imply that miR-423-5p has an oncogenic role and that urinary $m i R-423-5 p$ expression can act as a diagnostic indicator of bladder cancer. However, these findings remain unclear and should be validated in larger cohorts in the future.

\section{Materials and Methods}

\subsection{Urine Samples and Small RNA Extraction}

Eighty preoperative urine samples were obtained from patients who had undergone surgery in the Division of Urology, Department of Surgery, Kaohsiung Veterans General Hospital. Such clinical samples are routinely collected by the hospital's Biobank. In addition, 100 urine samples were obtained from healthy volunteer controls recruited in the Taiwan Biobank cohort study. Our study protocol was independently reviewed and approved by the hospital's institutional review board (IRB number: VGHKS18-CT12-05).

\subsection{Small RNA Extraction from Urine}

Urinary small RNA was extracted from $300 \mu \mathrm{L}$ of urine using a miRNeasy Serum/Plasma Kit (Qiagen, Valencia, CA, USA) according to the manufacturer's instructions. RNA was resuspended in $14 \mu \mathrm{L}$ of RNase-free $\mathrm{H}_{2} \mathrm{O}$.

\subsection{Generation of Small RNA Profiles Using Next-Generation Sequencing}

A total of 20 urine samples were collected from 10 patients with bladder cancer and 10 healthy controls; $300 \mu \mathrm{L}$ of each urine sample was then subjected to RNA extraction by using the miRNeasy Serum/Plasma Kit (Qiagen, Valencia, CA, USA). Finally, an Illumina small RNA preparation kit (Illumina, San Diego, CA, USA) was used to prepare a small RNA library, and the Illumina HiSeq platform (Illumina, San Diego, CA, USA) was then used for sequencing. First, quality control was performed on the generated sequence readings to remove low-quality readings. As mentioned, the sequence reads were then modified with $3^{\prime}$ linkers to produce clean reads. To study the miRNA expression profiles in 20 libraries, we mapped the qualified sequence readings back to human pre-miRNA (miRBase 19). We evaluated miRNA expression levels and presented them in transcripts per million (TPM); detailed information has been described in our previous studies [12,52].

\subsection{Pathway Enrichment Analysis}

The putative targets of the differentially expressed circulating miRNAs were identified using a target prediction tool. Then, the targets were subjected to pathway enrichment analysis by using the MIENTURNET (http://userver.bio.uniroma1.it/apps/mienturnet/, accessed on 12 April 2021) [53].

\subsection{TaqMan Real-Time PCR Assay}

After RNA extraction, $2 \mu \mathrm{L}$ of total RNA was subsequently used in a TaqMan Advanced cDNA Synthesis Kit (Applied Biosystems, Foster City, CA, USA) according to the manufacturer's instructions. Details on this process were described in our previous study [32]. 


\subsection{Statistical Analysis}

In this study, the expression levels of miRNA candidates in patients with bladder cancer and healthy controls determined through real-time PCR were evaluated using Student's $t$-tests. Differences were considered significant when $p<0.05$. The overall survival curves were examined using the Kaplan-Meier method or a log-rank test. A Cox proportional hazards model was used to determine the independent predictors of survival with factors determined to be significant in a univariate analysis employed as covariates.

Author Contributions: J.-T.L. executed this study and drafted the manuscript. K.-W.T. supervised the study and edited the manuscript. All authors have read and agreed to the published version of the manuscript.

Funding: This study was supported by grants from Kaohsiung Veterans General Hospital (VGHKS109101) and Taipei Tzu Chi Hospital, Buddhist Tzu Chi Medical Foundation (TCRD-TPE-109-66 and TCRD-TPE-MOST-108-17).

Institutional Review Board Statement: This study was approved by the institutional review board (IRB) of Kaohsiung Veterans General Hospital Kaohsiung, Taiwan (IRB number: VGHKS18-CT12-05)

Informed Consent Statement: All the specimens used in this study were obtained from biobank of Kaohsiung Veterans General Hospital and Taiwan Biobank. Informed consent was obtained from all patients by the biobanks.

Acknowledgments: The authors appreciate the assistance of the Biobank of Kaohsiung Veterans General Hospital for collecting urine from patients with bladder cancer, and Taiwan Biobank for collecting urine from healthy controls. The authors thank the Core Laboratory, Department of Research, Taipei Tzu Chi Hospital, Buddhist Tzu Chi Medical Foundation, for providing technical and co-facility support.

Conflicts of Interest: The authors declare no conflict of interests.

\section{References}

1. Choo, S.H.; Nishiyama, H.; Kitamura, H.; Chen, C.; Pu, Y.; Lee, H.; Jeong, B.C.; Kim, S.I. Practice pattern of non-muscle invasive bladder cancer in Japan, Korea and Taiwan: A Web-based survey. Int. J. Urol. 2019, 26, 1121-1127. [CrossRef] [PubMed]

2. Hung, C.-F.; Yang, C.-K.; Ou, Y.-C. Urologic cancer in Taiwan. Jpn. J. Clin. Oncol. 2016, 46, 605-609. [CrossRef] [PubMed]

3. Ng, K.; Stenzl, A.; Sharma, A.; Vasdev, N. Urinary biomarkers in bladder cancer: A review of the current landscape and future directions. Urol. Oncol. Semin. Orig. Investig. 2021, 39, 41-51. [CrossRef]

4. Wang, Y.; Yu, Y.; Ye, R.; Zhang, D.; Li, Q.; An, D.; Fang, L.; Lin, Y.; Hou, Y.; Xu, A.; et al. An epigenetic biomarker combination of PCDH17 and POU4F2 detects bladder cancer accurately by methylation analyses of urine sediment DNA in Han Chinese. Oncotarget 2016, 7, 2754-2764. [CrossRef] [PubMed]

5. O'Sullivan, P.; Sharples, K.; Dalphin, M.; Davidson, P.; Gilling, P.; Cambridge, L.; Harvey, J.; Toro, T.; Giles, N.; Luxmanan, C.; et al. A Multigene Urine Test for the Detection and Stratification of Bladder Cancer in Patients Presenting with Hematuria. J. Urol. 2012, 188, 741-747. [CrossRef]

6. $\quad$ Batista, R.; Vinagre, J.; Prazeres, H.; Sampaio, C.; Peralta, P.; Conceição, P.; Sismeiro, A.; Leão, R.; Gomes, A.; Furriel, F.; et al. Validation of a Novel, Sensitive, and Specific Urine-Based Test for Recurrence Surveillance of Patients With Non-Muscle-Invasive Bladder Cancer in a Comprehensive Multicenter Study. Front. Genet. 2019, 10, 1237. [CrossRef]

7. Darenkov, S.P.; Perlin, D.V.; Chernyshev, I.V.; Parshina, V.N.; Ivanov, A.V.; Iarovoŭ, S.K. [Efficacy of detection of specific nuclear protein of matrix 22 in the urine in diagnosis of urinary bladder cancer]. Urol. 2007, 48, 49-51.

8. Raitanen, M.-P.; Marttila, T.; Nurmi, M.; Ala-Opas, M.; Nieminen, P.; Aine, R.; Tammela, T.L.; Finnbladder Group. Human complement factor $\mathrm{h}$ related protein test for monitoring bladder cancer. J. Urol. 2001, 165, 374-377. [CrossRef]

9. Gajda, M.; Tyloch, F.; Jóźwicki, W.; Tyloch, J.; Sujkowska, R.; Skok, Z. Diagnostic value of urine cytology and urine carcinoembryonic antigen (CEA) level in the distinction between bladder cancer and urinary tract infection. Int. J. Occup. Med. Environ. Heal. 1995, 8, 103-108.

10. Hautmann, S.; Toma, M.; Gomez, M.F.L.; Friedrich, M.G.; Jaekel, T.; Michl, U.; Schroeder, G.L.; Huland, H.; Juenemann, K.-P.; Lokeshwar, V.B. Immunocyt and the HA-HAase Urine Tests for the Detection of Bladder Cancer: A Side-by-Side Comparison. Eur. Urol. 2004, 46, 466-471. [CrossRef]

11. Yekta, S.; Shih, I.H.; Bartel, D.P. MicroRNA-directed cleavage of HOXB8 mRNA. Science 2004, 304, 594-596. [CrossRef]

12. Leung, C.-M.; Li, S.-C.; Chen, T.-W.; Ho, M.-R.; Hu, L.-Y.; Liu, W.-S.; Wu, T.T.; Hsu, P.-C.; Chang, H.-T.; Tsai, K.-W. Comprehensive microRNA profiling of prostate cancer cells after ionizing radiation treatment. Oncol. Rep. 2014, 31, 1067-1078. [CrossRef] [PubMed] 
13. Cheng, W.-C.; Chung, I.-F.; Huang, T.-S.; Chang, S.-T.; Sun, H.-J.; Tsai, C.-F.; Liang, M.-L.; Wong, T.-T.; Wang, H.-W. YM500: A small RNA sequencing (smRNA-seq) database for microRNA research. Nucleic Acids Res. 2012, 41, D285-D294. [CrossRef] [PubMed]

14. Li, S.-C.; Liao, Y.-L.; Ho, M.-R.; Tsai, K.-W.; Lai, C.-H.; Lin, W.-C. miRNA arm selection and isomiR distribution in gastric cancer. BMC Genom. 2012, 13, 1-10. [CrossRef] [PubMed]

15. Chang, H.-T.; Li, S.-C.; Hong-Tai, C.; Pan, H.-W.; Ger, L.-P.; Hu, L.-Y.; Yu, S.-Y.; Li, W.-H.; Tsai, K.-W. Comprehensive analysis of microRNAs in breast cancer. BMC Genom. 2012, 13, S18. [CrossRef] [PubMed]

16. Li, S.-C.; Liao, Y.-L.; Chan, W.-C.; Ho, M.-R.; Tsai, K.-W.; Hu, L.-Y.; Lai, C.-H.; Hsu, C.-N.; Lin, W.-C. Interrogation of rabbit miRNAs and their isomiRs. Genomics 2011, 98, 453-459. [CrossRef]

17. Griffiths-Jones, S.; Hui, J.H.L.; Marco, A.; Ronshaugen, M. MicroRNA evolution by arm switching. EMBO Rep. 2011, 12, 172-177. [CrossRef]

18. Cloonan, N.; Wani, S.; Xu, Q.; Gu, J.; Lea, K.; Heater, S.J.; Barbacioru, C.; Steptoe, A.L.; Martin, H.C.; Nourbakhsh, E.; et al. MicroRNAs and their isomiRs function cooperatively to target common biological pathways. Genome Biol. 2011, 12, R126. [CrossRef]

19. Marco, A.; Hui, J.H.L.; Ronshaugen, M.; Griffiths-Jones, S. Functional Shifts in Insect microRNA Evolution. Genome Biol. Evol. 2010, 2, 686-696. [CrossRef]

20. Guo, L.; Li, H.; Liang, T.; Lu, J.; Yang, Q.; Ge, Q.; Lu, Z. Consistent isomiR expression patterns and 3' addition events in miRNA gene clusters and families implicate functional and evolutionary relationships. Mol. Biol. Rep. 2012, 39, 6699-6706. [CrossRef]

21. Chen, X.; Ba, Y.; Ma, L.; Cai, X.; Yin, Y.; Wang, K.; Guo, J.; Zhang, Y.; Chen, J.; Guo, X.; et al. Characterization of microRNAs in serum: A novel class of biomarkers for diagnosis of cancer and other diseases. Cell Res. 2008, 18, 997-1006. [CrossRef]

22. Gilad, S.; Meiri, E.; Yogev, Y.; Benjamin, S.; Lebanony, D.; Yerushalmi, N.; Benjamin, H.; Kushnir, M.; Cholakh, H.; Melamed, N.; et al. Serum MicroRNAs Are Promising Novel Biomarkers. PLoS ONE 2008, 3, e3148. [CrossRef]

23. Mitchell, P.S.; Parkin, R.K.; Kroh, E.M.; Fritz, B.R.; Wyman, S.K.; Pogosova-Agadjanyan, E.L.; Peterson, A.; Noteboom, J.; O'Briant, K.C.; Allen, A.; et al. Circulating microRNAs as stable blood-based markers for cancer detection. Proc. Natl. Acad. Sci. USA 2008, 105, 10513-10518. [CrossRef]

24. Chim, S.S.C.; Shing, T.K.F.; Hung, E.C.W.; Leung, T.-Y.; Lau, T.-K.; Chiu, R.W.K.; Lo, Y.M.D. Detection and Characterization of Placental MicroRNAs in Maternal Plasma. Clin. Chem. 2008, 54, 482-490. [CrossRef] [PubMed]

25. Pardini, B.; Cordero, F.; Naccarati, A.; Viberti, C.; Birolo, G.; Oderda, M.; Di Gaetano, C.; Arigoni, M.; Martina, F.; Calogero, R.A.; et al. microRNA profiles in urine by next-generation sequencing can stratify bladder cancer subtypes. Oncotarget 2018, 9, 20658-20669. [CrossRef] [PubMed]

26. Lopez-Beltran, A.; Cheng, L.; Gevaert, T.; Blanca, A.; Cimadamore, A.; Santoni, M.; Massari, F.; Scarpelli, M.; Raspollini, M.R.; Montironi, R. Current and emerging bladder cancer biomarkers with an emphasis on urine biomarkers. Expert Rev. Mol. Diagn. 2019, 20, 231-243. [CrossRef]

27. Juracek, J.; Peltanova, B.; Dolezel, J.; Fedorko, M.; Pacik, D.; Radova, L.; Vesela, P.; Svoboda, M.; Slaby, O.; Stanik, M. Genome-wide identification of urinary cell-free microRNAs for non-invasive detection of bladder cancer. J. Cell. Mol. Med. 2018, 22, $2033-2038$. [CrossRef] [PubMed]

28. Du, L.; Jiang, X.; Duan, W.; Wang, R.; Wang, L.; Zheng, G.; Yan, K.; Wang, L.; Li, J.; Zhang, X.; et al. Cell-free microRNA expression signatures in urine serve as novel noninvasive biomarkers for diagnosis and recurrence prediction of bladder cancer. Oncotarget 2017, 8, 40832-40842. [CrossRef]

29. Luo, Y.; Zeng, G.; Wu, S. Identification of Microenvironment-Related Prognostic Genes in Bladder Cancer Based on Gene Expression Profile. Front. Genet. 2019, 10, 1187. [CrossRef] [PubMed]

30. Cronise, K.E.; Hernandez, B.G.; Gustafson, D.L.; Duval, D.L. Identifying the ErbB/MAPK Signaling Cascade as a Therapeutic Target in Canine Bladder Cancer. Mol. Pharmacol. 2019, 96, 36-46. [CrossRef]

31. Kao, H.-W.; Pan, C.-Y.; Lai, C.-H.; Wu, C.-W.; Fang, W.-L.; Huang, K.-H.; Lin, W.-C. Urine miR-21-5p as a potential non-invasive biomarker for gastric cancer. Oncotarget 2017, 8, 56389-56397. [CrossRef]

32. Lee, S.-Y.; Lu, R.-B.; Wang, L.-J.; Chang, C.-H.; Lu, T.; Wang, T.-Y.; Tsai, K.-W. Serum miRNA as a possible biomarker in the diagnosis of bipolar II disorder. Sci. Rep. 2020, 10, 1-10. [CrossRef] [PubMed]

33. Tsai, K.-W.; Liao, Y.-L.; Wu, C.-W.; Hu, L.-Y.; Li, S.-C.; Chan, W.-C.; Ho, M.-R.; Lai, C.-H.; Kao, H.-W.; Fang, W.-L.; et al. Aberrant expression of miR-196a in gastric cancers and correlation with recurrence. Genes Chromosom. Cancer 2011, 51, 394-401. [CrossRef]

34. Shee, K.; Seigne, J.D.; Karagas, M.R.; Marsit, C.J.; Hinds, J.W.; Schned, A.R.; Pettus, J.R.; Armstrong, D.A.; Miller, T.W.; Andrew, A.S. Identification of Let-7f-5p as a novel biomarker of recurrence in non-muscle invasive bladder cancer. Cancer Biomark. 2020, 29, 101-110. [CrossRef] [PubMed]

35. Fredsøe, J.; Rasmussen, A.K.I.; Mouritzen, P.; Borre, M.; Ørntoft, T.; Sørensen, K.D. A five-microRNA model (pCaP) for predicting prostate cancer aggressiveness using cell-free urine. Int. J. Cancer 2019, 145, 2558-2567. [CrossRef]

36. Yun, S.J.; Jeong, P.; Kim, W.-T.; Kim, T.H.; Lee, Y.-S.; Song, P.H.; Choi, Y.-H.; Kim, I.Y.; Moon, S.-K.; Kim, W.-J. Cell-free microRNAs in urine as diagnostic and prognostic biomarkers of bladder cancer. Int. J. Oncol. 2012, 41, 1871-1878. [CrossRef] [PubMed]

37. Mengual, L.; Lozano, J.J.; Ingelmo-Torres, M.; Gazquez, C.; Ribal, M.J.; Alcaraz, A. Using microRNA profiling in urine samples to develop a non-invasive test for bladder cancer. Int. J. Cancer 2013, 133, 2631-2641. [CrossRef] [PubMed] 
38. Ghorbanmehr, N.; Gharbi, S.; Korsching, E.; Tavallaei, M.; Einollahi, B.; Mowla, S.J. miR-21-5p, miR-141-3p, and miR-205-5p levels in urine-promising biomarkers for the identification of prostate and bladder cancer. Prostate 2019, 79, 88-95. [CrossRef]

39. Sun, Z.; Shi, K.; Yang, S.; Liu, J.; Zhou, Q.; Wang, G.; Song, J.; Li, Z.; Zhang, Z.; Yuan, W. Effect of exosomal miRNA on cancer biology and clinical applications. Mol. Cancer 2018, 17, 1-19. [CrossRef]

40. Knowles, M.A.; Hurst, C.D. Molecular biology of bladder cancer: New insights into pathogenesis and clinical diversity. Nat. Rev. Cancer 2015, 15, 25-41. [CrossRef]

41. Zou, X.; Zhu, D.; Zhang, H.; Zhang, S.; Zhou, X.; He, X.; Zhu, J.; Zhu, W. MicroRNA expression profiling analysis in serum for nasopharyngeal carcinoma diagnosis. Gene 2020, 727, 144243. [CrossRef]

42. Zou, X.; Xia, T.; Li, M.; Wang, T.; Liu, P.; Zhou, X.; Huang, Z.; Zhu, W. MicroRNA profiling in serum: Potential signatures for breast cancer diagnosis. Cancer Biomark. 2021, 30, 41-53. [CrossRef]

43. Zhang, H.; Zou, X.; Wu, L.; Zhang, S.; Wang, T.; Liu, P.; Zhu, W.; Zhu, J. Identification of a 7-microRNA signature in plasma as promising biomarker for nasopharyngeal carcinoma detection. Cancer Med. 2019, 9, 1230-1241. [CrossRef]

44. Li, M.; Zou, X.; Xia, T.; Wang, T.; Liu, P.; Zhou, X.; Wang, S.; Zhu, W. A five-miRNA panel in plasma was identified for breast cancer diagnosis. Cancer Med. 2019, 8, 7006-7017. [CrossRef]

45. Li, F.; Bai, M.; Xu, J.; Zhu, L.; Liu, C.; Duan, R. Long-Term Exercise Alters the Profiles of Circulating Micro-RNAs in the Plasma of Young Women. Front. Physiol. 2020, 11, 372. [CrossRef] [PubMed]

46. Zhang, X.; Wang, S.; Wang, H.; Cao, J.; Huang, X.; Chen, Z.; Xu, P.; Sun, G.; Xu, J.; Lv, J.; et al. Circular RNA circNRIP1 acts as a microRNA-149-5p sponge to promote gastric cancer progression via the AKT1/mTOR pathway. Mol. Cancer 2019, 18, 1-24. [CrossRef] [PubMed]

47. Ye, X.; Chen, X. miR-149-5p inhibits cell proliferation and invasion through targeting GIT1 in medullary thyroid carcinoma. Oncol. Lett. 2018, 17, 372-378. [CrossRef] [PubMed]

48. Liu, L.; Chen, Y.; Li, Q.; Duan, P. IncRNA HNF1A-AS1 modulates non-small cell lung cancer progression by targeting miR-1495p/Cdk6. J. Cell. Biochem. 2019, 120, 18736-18750. [CrossRef]

49. Li, S.; Zeng, A.; Hu, Q.; Yan, W.; Liu, Y.; You, Y. miR-423-5p contributes to a malignant phenotype and temozolomide chemoresistance in glioblastomas. Neuro-Oncology 2017, 19, 55-65. [CrossRef]

50. Wang, X.; Peng, L.; Gong, X.; Zhang, X.; Sun, R.; Du, J. miR-423-5p Inhibits Osteosarcoma Proliferation and Invasion through Directly Targeting STMN1. Cell. Physiol. Biochem. 2018, 50, 2249-2259. [CrossRef]

51. Tang, X.; Zeng, X.; Huang, Y.; Chen, S.; Lin, F.; Yang, G.; Yang, N. miR-423-5p serves as a diagnostic indicator and inhibits the proliferation and invasion of ovarian cancer. Exp. Ther. Med. 2018, 15, 4723-4730. [CrossRef] [PubMed]

52. Leung, C.-M.; Chen, T.-W.; Li, S.-C.; Ho, M.-R.; Hu, L.-Y.; Liu, W.-S.; Wu, T.T.; Hsu, P.-C.; Chang, H.-T.; Tsai, K.-W. MicroRNA expression profiles in human breast cancer cells after multifraction and single-dose radiation treatment. Oncol. Rep. 2014, 31, 2147-2156. [CrossRef] [PubMed]

53. Licursi, V.; Conte, F.; Fiscon, G.; Paci, P. MIENTURNET: An interactive web tool for microRNA-target enrichment and networkbased analysis. BMC Bioinform. 2019, 20, 1-10. [CrossRef] [PubMed] 